\section{The effects of delay and difficulty on discrimination learning and stimulus generalization*}

\author{
DONALD G. WILDEMANN and JAMES G. HOLLAND \\ University of Pittsburgh, Pittsburgh, $\mathrm{Pa} .15213$
}

Following training on an easy size discrimination, pigeons were matched on the basis of stimulus control by the positive stimulus following generalization tests. Three Ss were immediately retrained on a more difficult discrimination along the same dimension, while the remaining three Ss were retrained after a 6-month delay. The 6-month-delay group took longer to learn the more difficult discrimination and displayed less stimulus control on a subsequent generalization test.

Relatively little research has been done on memory for simple operant discriminations or on the influence of the passage of time between learning a gross discrimination and learning a finer discrimination. This study examines the effects of training a fine discrimination immediately or 6 months after training on a relatively coarser discrimination. The study also measures the result of this retraining on generalization gradients.

Previous findings suggest that the generalization gradient is flatter if a sufficient delay intervenes between training and testing, whether the test follows training only on a positive stimulus (Thomas \& Lopez, 1962) or follows discrimination training (Thomas \& Burr, 1969; Honig, 1969), although, in the latter case, one study failed to find this result (Thomas et al 1960). If a delay does flatten the gradient, we should expect retarded learning of a fine discrimination when a delay intervenes after learning a coarse discrimination.

In the present study, pigeons were either immediately shifted from an easy to a more difficult discrimination or shifted after a 6-month delay.

\section{SUBJECTS}

Six adult experimentally naive White Carneaux pigeons were maintained at $80 \%$ of their free-feeding weights throughout the experiment.

\section{APPARATUS}

A Grason-Stadler pigeon chamber with two keys was modified to accept inline projectors which could transilluminate the key. with any of 10 white circles. The si:-allest circle diameter (Stimulus 1) was $0.185 \mathrm{in}$. and each succeeding circle (Stimuli 2-10) increased in diameter by 0.035 in.

\section{PROCEDURE}

Training on the

Coarse Discrimination

\footnotetext{
*This research was supported at the Learning Research and Development Center by OE Contract No. 410158 .
}

After magazine training, each $\mathrm{S}$ was trained for 7 days to peck at the positive stimulus ( $\mathrm{S}+$, Stimulus 3 ), which was alternated randomly between the two keys. Both keys were employed throughout this study because the data were needed for comparison in another study on transposition. Pecks were reinforced on a 30-sec VI schedule of reinforcements per session. Reinforcement was a 3.75 -sec period of access to a hopper of mixed grains. Trials were $30 \mathrm{sec}$ in duration and separated by an intertrial interval of variable duration (mean of $10 \mathrm{sec}$ ) with the chamber darkened. Responses during the intertrial interval delayed the onset of the next trial for $10 \mathrm{sec}$ In the eighth session, the negative stimulus (S-, Stimulus 1) was introduced, and $S+$ and $S-$ trials were alternated randomly. On any trial, only one of the two keys was transilluminated with a stimulus.

For three $\mathrm{Ss}$, responses to the $\mathrm{S}-$ were extinguished; they met critexion when the total number of $\mathrm{S}+$ responses during one session was at least 20 times greater than the number of $\mathrm{S}-$ responses during that session. For the other three $\mathrm{Ss}$, approaches to $\mathrm{S}-$ were extinguished by the blackout technique (Lyons, 1968). These birds met criterion when the total number of responses to $S+$ were at least 20 times greater than the number of $S-$ approaches. Both methods were found to produce similar generalization gradients when used with these stimuli (Wildemann \& Holland, 1970).

Generalization Tests:

Coarse Discrimination

Each $S$ was tested three times during the preliminary training. The first and third tests consisted of stimulus pairs on each trial, with the number of responses to each stimulus being recorded. Ten trials were given with each pair of stimuli. Generalization gradients were calculated by summing the total number of responses to each stimulus, reinforcement. Each $S$ obtained 50 e.g., the total number of responses to Stimulus 3 was the sum of the responses to Stimulus 3 when Pair 2.3 and Pair 3-4 were presented. The second test was a standard generalization test, with only one stimulus present per trial. During this test, each stimulus was presented on 10 different trials, while the key position with the stimulus was alternated randomly. Since each test was conducted without reinforcement, responding was reestablished by separating each test with an additional day of discrimination training. Training on the

Fine Discrimination

Following preliminary training and testing, Ss were matched on the basis of the results of the first and third test gradients since these gradients represent performance both at the beginning and at the end of this test sequence. One bird from each pair was assigned randomly to the no-delay group, the other to the 6-month-delay group. On the day following the third test, the no-delay group began the second phase of discrimination training. The $\mathrm{S}+$ value remained the same, but the new $\mathrm{S}-$ was Stimulus 2 . Thus, for the second phase of discrimination training, the difference between the $\mathrm{S}+$ and $\mathrm{S}-$ was 0.035 in., or half the difference for the coarse discrimination. During this second phase of training, responses to the new S- were extinguished for all Ss. The criterion was again a 20 to 1 ratio of $\mathrm{S}+$ to $\mathrm{S}-$ responses during one session. Six months after the third test, the delay group began the second phase of discrimination training. Their procedure was the same as the no-delay group.

Generalization Test:

Fine Discrimination

The fourth test had two parts and was presented after criterion had been reached on the finer discrimination. Part 4 a was a conventional generalization test with five trials per stimulus value, while Part $4 \mathrm{~b}$ presented each stimulus pair five times. Test $4 \mathrm{~b}$ immediately followed Test $4 \mathrm{a}$.

\section{RESULTS}

\section{Coarse Discrimination}

Figure 1 shows the composite gradients obtained for each group. The diagonal line in each gradient shows the modal value of that gradient. Tests 1-3 were presented after training on the coarse discrimination. On the first test, five of the six Ss showed some evidence of peak shift. In Fig. 1, this can be seen most clearly in the generalization gradient for the 6-month-delay group where the mode of the responses is shifted to Stimulus 4, away from both the positive and negative stimuli ( 3 and 1 , respectively). Grouping the individual 
gradients makes tinis trend less apparent for the no-delay group, although Fig. 1 shows that there were almost as many responses to Stimulus 5 as to the positive stimulus. On Test 2, after an additional day of discrimination training, the percentage of the responses to the positive stimulus increased by about $10 \%$ for all birds. By the third test, most responses were to the positive stimulus, and there were few responses to any extreme values (e.g., Stimuli 6-10). On each of the three tests, less than $10 \%$ of the total responses were emitted to Stimulus 2, the negative stimulus on the fine discrimination.

\section{Fine Discrimination}

Table 1 shows the number of days to criterion and the number of responses to the negative stimulus during the second phase of training. All Ss took at least 3 days to learn the fine discrimination despite the fact that they emitted less than $10 \%$ of their responses to the new negative stimulus value during the first three generalization tests. The 6-month-delay group had many more errors than the no-delay group $(9,807$ as compared with 2,821). The delay group tended to take longer to learn the fine discrimination. The delay, therefore, may retard the acquisition of the fine discrimination.

Figure 1 shows the gradients for the delay and no-delay groups. The no-delay group continued to emit most of their responses to the positive stimulus on both parts of the test. On Part $4 \mathrm{a}, 60 \%$ of their total responses occurred to Stimulus 3, while in Part $4 \mathrm{~b}, 82 \%$ of their total responses were emitted to the positive stimulus. This group also made very few responses to the more extreme Stimuli $6-10$, emitting only $1 \%$ of their total responses to these values throughout the test. There was far less stimulus control for the 6-month-delay group. On Test $4 \mathrm{a}$, only $25 \%$ of the total responses were emitted to the positive stimulus, and a relatively larger number of responses were emitted to the more extreme stimuli [6-10 (35\%)]. Although less apparent, this effect is also found in the second half of the test ( $4 \mathrm{~b})$, where $11 \%$ of the total responses still occurred to values above Stimulus 6 and the responses to $S+$ are 18 percentage points less than for the no-delay group.

\section{DISCUSSION}

A delay after original training appears to flatten the generalization gradient. When the delay intervenes after the initial training but before the generalization test, relatively fewer responses occur to the discriminative stimulus $(\mathrm{S}+)$ and more to other

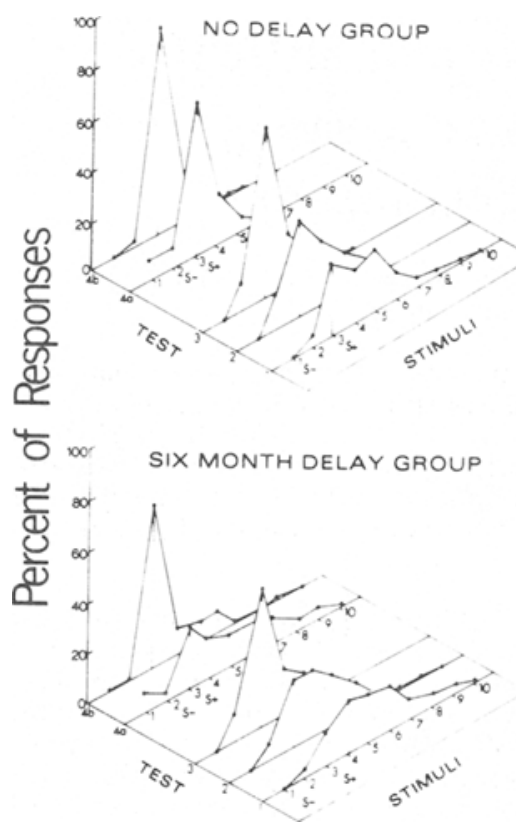

Fig. 1. Composite generalization gradients for the 6-month-delay and the no-delay groups,

stimuli (Thomas \& Lopez, 1962; Thomas \& Burr, 1969; Honig, 1969). The results reported here confirm an implication of this lessening of stimulus control. A long delay between learning one discrimination and progressing to a finer discrimination increases the time required to learn the finer discrimination; and the delay increases the number of responses to the negative stimulus during training on the finer discrimination. The increase in $\mathrm{S}-$ responding after the delay, as well as the assumed spread of generalization (cf. Thomas \& Burr, 1969), may result from dissipation with time of the inhibition established in the original learning. Moreover, after the fine discrimination is established, the effects of the delay persist on a subsequent generalization test, with less responding to $\mathrm{S}+$ and more to other stimulus values than is found when no delay occurs in training. The spread in the gradient could be, in part, the result of the increase in $\mathrm{S}$ - responses caused by the delay. The temptation to attribute all of the spread in the gradient of the delay group to greater $S$ - responding is frustrated by the fact that one $S$ in the delay group had approximately the same number of errors as the no-delay Ss; yet this $\mathrm{S}$ still showed a flattened gradient on the last generalization iest. Nevertheless, the delay between learning the coarse and the fine discriminations resulted in a flatter gradient, whether as a direct effect of the delay or as an effect of more $S-$ responding in the second discrimination.

There is an implication in educational practice in these results when one is reminded that educational practice generally, and programmed instruction most specifically, arranges for gradual progression from easy to difficult (or from coarse discriminations to finer discriminations). These results suggest that it would be poor practice to introduce delays between early and late stages in the learning sequence. Thus, any automatic assumption based on the rote-learning literature that spaced learning is superior is not always warranted.

\section{REFERENCES}

HONIG, W. K. Attentional factors governing the slope of the generalization gradient. In R. M. Gilbert and N. S. Sutherland (Eds.), Animal discrimination learning. New. York: Academic Press, 1969 Pp. 36-63.

LYONS, J. Stimulus generalization as a function of discrimination learning with and without errors. Science, 1969, 163. 490-491.

THOMAS, D. R., \& BURR, D. E. S. Stimulus generalization as a function of the delay between training and testing: A reevaluation. Journal of the Experimental Analysis of Behavior, 1969, 12,105-109. THOMAS, D. R. \& LOPEZ, L. J. The effects of delayed testing on generalization slope. Journal of Comparative \& Physiological Psychology. $1962,55,541-544$

THOMAS, D. R.. OST. J., \& THOMAS, D. Stimulus generalization as a function of the time between training and testing procedures. Journal of the Experimental Analysis of Behavior, $1960,3,9-14$.

WILDEMANN, D. G., \& HOLLAND, J, G. The role of $S-$ responding in transposition and peak shift. Paper presented at the Eastern Psychological Association meeting, Atlantic City, 1970.

Table 1

Performance to Criterion on the Fine Discrimination

\begin{tabular}{llcr}
\hline & Procedure & $\begin{array}{c}\text { Days to } \\
\text { Criterion }\end{array}$ & $\begin{array}{c}\text { Total Number of S } \\
\text { Responses to Criterion }\end{array}$ \\
\hline S 51 & No Delay & 6 & 936 \\
S 52 & No Delay & 3 & 1308 \\
S 53 & No Delay & 3 & 577 \\
S 45 & 6-Month Delay & 3 & 1246 \\
S 46 & 6-Month Delay & 7 & 5609 \\
S 47 & 6-Month Delay & 7 & 2592 \\
\hline
\end{tabular}

